\title{
Isolated epispadias
}

INSERM

\section{Source}

INSERM. (1999). Orphanet: an online rare disease and orphan drug data base. Isolated epispadias. ORPHA:93928

Epispadias is a congenital genitourinary malformation belong ing to the spectrum of the exstrophy-epispadias complex (EEC; see this term) and is characterized in males by an ectopic meatus or a mucosal strip in place of the urethra on the penile dorsum and in females by bifid clitoris and a variable cleft of the urethra. 